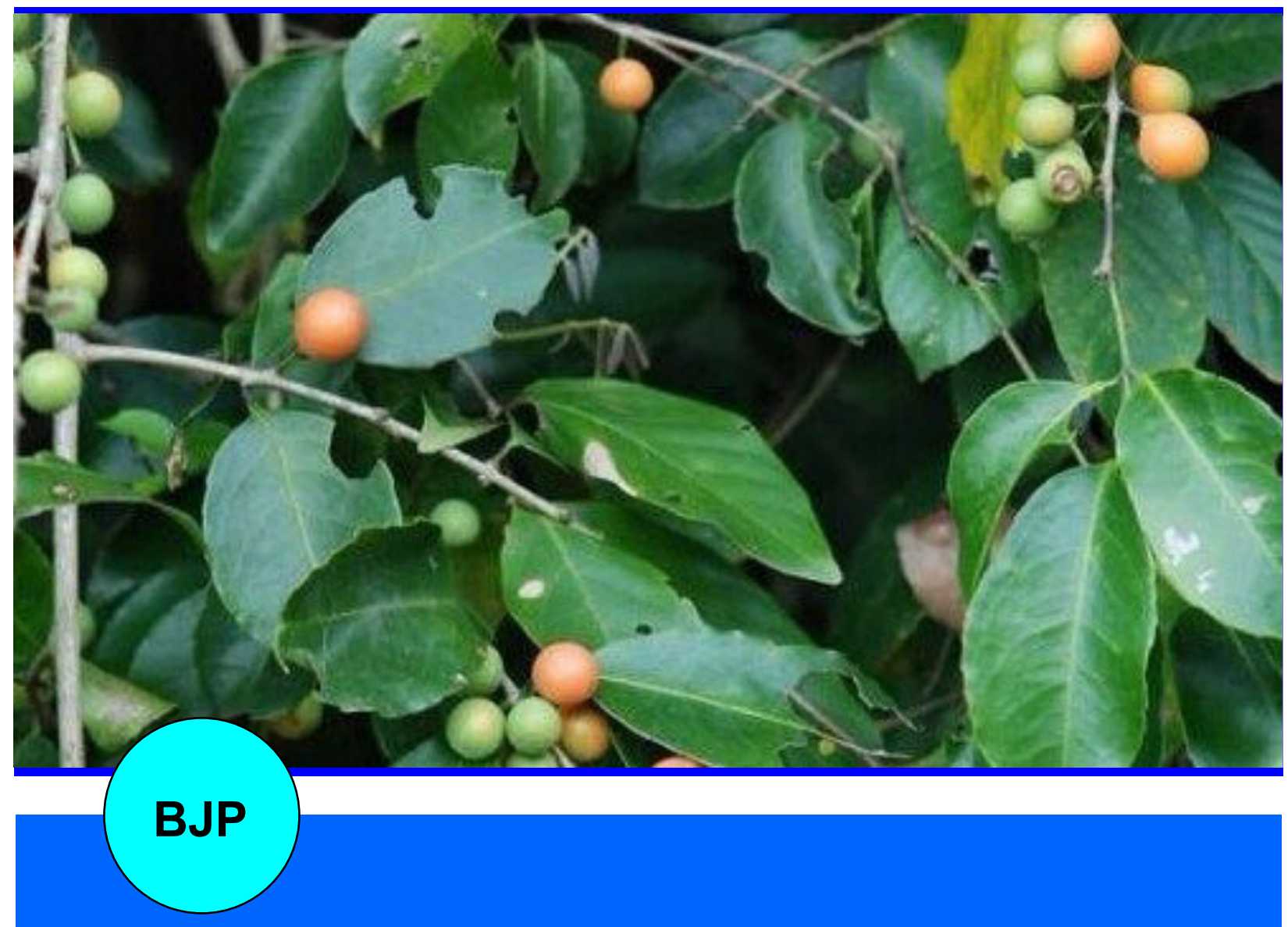

Bangladesh Journal of Pharmacology

Research Article

Hypoglycemic effect of poly-herbal combination in streptozotocin- induced diabetic rats 
Abstracted/indexed in Academic Search Complete, Asia Journals Online, Bangladesh Journals Online, Biological Abstracts, BIOSIS Previews, CAB Abstracts, Current Abstracts, Directory of Open Access Journals, EMBASE/Excerpta Medica, Google Scholar, HINARI (WHO), International Pharmaceutical Abstracts, Open J-gate, Science Citation Index Expanded, SCOPUS and Social Sciences Citation Index;

ISSN: $1991-0088$

\title{
Hypoglycemic effect of poly-herbal combination in streptozotocin- induced diabetic rats
}

\author{
Gino A. Kurian
}

Department of Biochemistry, School of Chemical and Biotechnology, SASTRA University, Thanjavur, Tamil Nadu, India.

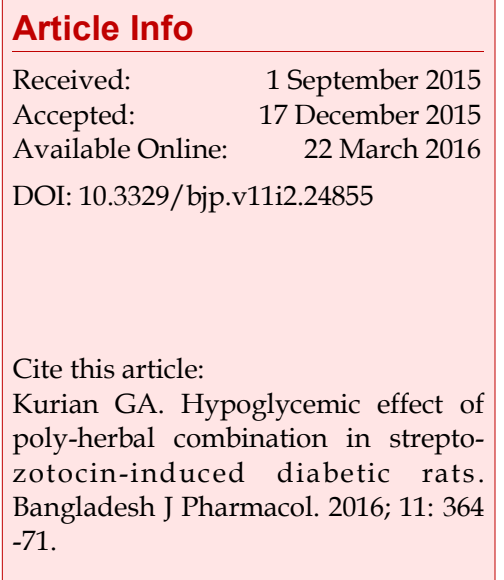

\section{Abstract}

The present study evaluates the combinatorial effect of a poly-herbal combination with multiple therapeutic effects as a hypoglycemic and hypolipidemic agent. Herbal combination of Salacia oblonga, Tinospora cordifolia, Emblica officinalis, Curcuma longa and Gymnema sylvestre was prepared and administered to streptozotocin $(55 \mathrm{mg} / \mathrm{kg}$, i.p.)-induced diabetic rats, at a dose of 100 $\mathrm{mg} / \mathrm{kg}$, for four weeks. The poly-herbal combination significantly elevated the plasma insulin $(90 \%)$ and reduced serum glucose $(42 \%)$, cholesterol $(49 \%)$, triglycerides (43\%), LDL cholesterol (62.5\%) and plasma apo B/apo A in the diabetic rats. The liver lipogenic enzymes like HMG CoA reductase and glucose-6-phosphatase significantly declined $(\mathrm{p}<0.05)$ in their activity while glucose-6-phosphate dehydrogenase and malic enzymes showed higher activity compared to the diabetic control. The results suggest a significant hypoglycemic and hypolipidemic property for the poly-herbal combination.

\section{Introduction}

Type 2 diabetes is characterized by hyperglycemia, hyperinsulinemia, obesity and insulin resistance; therefore, multiple targeted drug therapy would be promising (Edgerton et al., 2009). In Indian system of traditional medicine, plant formulation and their combined extracts are used as a drug of choice rather than individual. Various herbal formulations such as diasulin (Pari and Saravanan, 2004), hyponidd (Babu and Prince, 2004) are well-known for their anti-diabetic effects. Recently, there has been a shift from the onedrug-one-target paradigm towards combination therapy to achieve therapeutic benefits for several diseases. Here, we tested poly-herbal combination comprises of the extracts of known anti-diabetic plants such as Salacia oblonga Wall (Celastraceae), Tinospora cordifolia Thunb. (Menispermaceae), Emblica officinalis Gaertn. (Euphorbiaceae), Curcuma longa Linn. (Zingiberaceae) and Gymnema sylvestre R.Br. (Asclepiadaceae) in diabetic rats.

\section{Materials and Methods}

\section{Chemical}

Streptozotocin was purchased from Sigma-Aldrich. All other commercial reagents used were of analytical grade.

\section{Animals}

To demonstrate the anti-diabetic property of polyherbal combination G-400 and its effect on blood glucose levels, male albino Wistar rats aged 7 to 8 weeks (180-200 g) were purchased from the animal division of King's Institute, Chennai. Animals were kept in polycarbonate cages at an ambient temperature of $25-30^{\circ} \mathrm{C}$ and $45-55 \%$ relative humidity with a 12 hours light/dark cycle. Animals were fed pelleted diet (Sai Durga Feeds and Foods, Bangalore, India.) and water ad libitum.

\section{Poly-herbal drug G-400}

G-400 contains a mixture of the following herbs 
expressed as \%dry weight: 30\% S. oblonga leaves, 10\% T. cordifolia, $10 \%$ E. officinalis, $10 \%$ C. longa and $40 \%$ G. sylvestre prepared by Kerala Ayurvedic Pharmaceutical Company, Kerala, India. The herbal formulation of the anti-diabetic plants were prepared and named as G-400 based on the guidelines prescribed by ayurvedic antidiabetic formulations (Modak et al., 2007).

\section{Induction of experimental diabetes}

The animals were fasted overnight, and diabetes was induced by a single intraperitoneal injection of a freshly prepared solution of streptozotocin $(55 \mathrm{mg} / \mathrm{kg})$ in $0.1 \mathrm{M}$ citrate buffer ( $\mathrm{pH}$ 4.5) (Rakieten et al., 1963). Control rats were injected with citrate buffer alone. On the third day of streptozotocin injection, the rats were fasted for 6 hours and blood was taken from the tail vein. Rats with moderate diabetes, having hyperglycemia (blood glucose range $250-400 \mathrm{mg} / \mathrm{dL}$ ) were taken for further experiment. The rats were monitored for 15 days to stabilize the diabetic condition.

In the experiment, a total of 24 rats (18 diabetic surviving rats and 6 normal rats) were used. The rats were divided among 4 groups consisting of 6 animals within each group as follows: Group I (normal rats); Group II (diabetic untreated rats); Group III (diabetic treated G$400(100 \mathrm{mg} / \mathrm{kg})$ daily using an intragastric tube for 4 weeks); Group IV (diabetic treated with glibenclamide $(0.025 \mathrm{mg} / \mathrm{kg})$ daily using an intragastric tube for 4 weeks).

At the end of 4 weeks, the animals were fasted overnight and sacrificed. Blood samples were collected in 2 different tubes, one with anticoagulant, potassium oxalate and sodium fluoride for plasma and another without anticoagulant for serum separation. The blood was then centrifuge at 3,000 rpm for $20 \mathrm{~min}$ using refrigerated centrifuge at $4^{\circ} \mathrm{C}$ to separate the plasma and serum, used for various biochemical studies.

\section{Biochemical analysis}

Blood biochemical parameters were estimated by using diagnostic kits. Fasting blood glucose was estimated by the oxidase/peroxidise method (Trinder, 1969) and glycosylated hemoglobin by ion exchange method as per the standard protocol described in the kit from BioSystems Diagnostics Pvt. Ltd, India. Plasma insulin level was assayed by the Radioimmunoassay (RIA) kit (Diasorin, Saluggia, Italy), using human insulin as standard. Serum high density lipoproteins, low density lipoproteins + very low density lipoproteins were separated by the standard protocol described by Wranick and Alber (1978) and Falholt et al., (1973) procedure was used to extract and estimate serum fatty acids by utilizing standard diagnostic kits supplied by Dr. Reddy's Diagnostic Lab, Hyderabad, India. Apolipoprotein $\mathrm{A}_{1}$ and apolipoprotein $\mathrm{B}_{100}$ were estimated by immune-turbidometric assay kit.
Hepatic cholesterol

Cholesterol in the liver tissues were extracted by the method of Folch et al., (1957), and estimated by the method of Allain et al., (1974). By using chloroform/ methanol mixture lipids were extracted from $100 \mathrm{mg}$ of liver. Cholesterol was then determined using a colorimetric assay kit performed according to the manufacturer's instruction.

\section{Hepatic triglycerides}

Van Handel's method (1961) was used in the estimation of triglycerides after removing phospholipids with flurosil. Briefly, the hepatic tissue samples were homogenized in 2:1 chloroform-methanol solution and after separating the different phases, triglycerides were measured by using a commercially available colorimetric reagent.

\section{Protein estimation}

Lowry's methods (Lowry et al., 1951) was used to measure protein concentration in the hepatic tissue by using Folins reagents (Biorad, CA,USA) and measure the absorbance at $660 \mathrm{~nm}$.

\section{HMG CoA reductase}

Glutaryl co-enzyme reductase activity was estimated by measuring the ratio of 3-hydroxy-3-methyl glutaryl coenzymes to mevalonate as described (Kurian et al., 2005). Briefly, the hepatic HMG-CoA react with hydroxylamine reagent at alkaline $\mathrm{pH}$ resulting hydroxamic acid by formation of complexes with ferric salts measured at $540 \mathrm{~nm}$. The hepatic mevalonate was estimated by reaction with the same reagent but at $\mathrm{pH}$ 2.1. At this $\mathrm{pH}$, the lactone form of mevalonate readily reacts with hydroxylamine to form the hydroxamate.

\section{Glucose-6-phosphatase}

Activities of glucose-6-phosphatase was measured by previously described standard protocol (Garland et al., 1974). The reaction mixture consist of $0.1 \mathrm{M}$ phosphatebuffered saline ( $\mathrm{pH} 7.4), 0.1 \mathrm{M}$ glucose-6-phosphate solution and the sample were incubated in a $37^{\circ} \mathrm{C}$ water bath for $15 \mathrm{~min}$. The reaction was stopped by the addition of $1 \mathrm{~mL}$ of $10 \%$ trichloroacetic acid (TCA), followed by chilling in ice and centrifuging at $3000 \times \mathrm{g}$ for $10 \mathrm{~min}$.

Glucose-6-phosphate dehydrogenase and malic enzyme

The NADPH-linked activities of glucose-6-phosphate dehydrogenase (G6PDH) (Schroeder et al., 1984) and malic enzyme (ME) (Pongratz et al., 2007) were investigated after the increase in absorption at $340 \mathrm{~nm}$. For the determination of G6PDH activity, a buffer containing $50 \mathrm{mM}$ Tris- $\mathrm{HCl}, \mathrm{pH} 8,1 \mathrm{mM} \mathrm{MgCl}$, and 5 mM NADP was mixed with $60 \mu \mathrm{g}$ of cytosolic protein/ $\mathrm{mL}$, and the reaction was started with glucose-6- 
phosphate acid ( $8 \mathrm{mM}$ final concentration) at $37^{\circ} \mathrm{C}$. ME activity was measured in a buffer containing $50 \mathrm{mM}$ Tris- $\mathrm{HCl}, \mathrm{pH} 7.4,1 \mathrm{mM} \mathrm{MnCl} 2,5 \mathrm{mM}$ NADP, and 180 $\mu \mathrm{g}$ protein $/ \mathrm{mL}$. The reaction was started with L-malic acid ( $8 \mathrm{mM}$ final concentration) at room temperature.

Lipoprotein lipase

Lipoprotein lipase (Mayes and Fells, 1968) was assayed by standard protocol. The standard reaction mixture contained $0.2 \mathrm{mM}$ DMPTB, $0.8 \mathrm{mM}$ DTNB, $1 \mathrm{mM}$ EDTA, $0.05 \%$ Triton $X-100$, and $50 \mathrm{mM}$ Tris- $\mathrm{Cl}_{2}$, $\mathrm{pH} 7.5$. Microplate wells were filled with $180 \mu \mathrm{L}$ of this mixture and $20 \mu \mathrm{L}$ of the enzyme sample was added to each well. The microplate was immediately transferred to a $37^{\circ} \mathrm{C}$ incubator to start the reaction. After the indicated period of incubation, the absorbance of each well at 405 nm was measured.

\section{Statistics}

All data were expressed as the mean \pm SD. Statistical analysis was performed using one-way analysis of variance (ANOVA) for multiple comparisons among the groups.

\section{Results}

\section{Effect on fasting blood glucose and plasma insulin level} in diabetic rats

The effect of G-400 on fasting blood glucose in control and experimental diabetic rat are shown in Figure 1. A normal fasting blood glucose level was observed in the rats treated with the drug as compared to the diabetic animals $(p<0.01)$. In correspondence to fasting blood glucose, plasma insulin level was significantly increased after drug treatment compared to diabetic control $(\mathrm{p}<0.01)$.

Effect on lipid profile and apoproteins in the blood samples of diabetic rats

Diabetes induced by streptozotocin resulted in a significant elevation in the levels of total cholesterol (TC), LDL + VLDL cholesterol (LDL + VLDL C , triglycerides (TG) and free fatty acids (FFA) in comparison to the normal control group. After treatment of diabetic group with $\mathrm{G}-400$, a significant reduction $(\mathrm{p}<0.05$ in $\mathrm{TC}$, LDL + VLDLC, TG and FFA was observed compared to the untreated diabetic group (Figure 2). In fact, the effect of G-400 on the lipid profile was as good as to the standard drug, glibenclamide.

The Apo A1 level in blood was significantly lower and Apo B100 and Apo B/Apo A were significantly higher in the diabetic rat than those of the normal control animals (Figure 3). Apo A1, Apo B100 and its ratio were normalized to the control level by the administration of G-400 and the protection was even effective than the animals administrated with standard drug.

The effects of G-400 on cholesterol, triglycerides levels and HMG CoA reductase and lipoprotein lipase activities were measured in rat liver (Figure 4). Rats administered with streptozotocin showed a significant elevation in the concentration of cholesterol and triglycerides with a corresponding increased HMG CoA reductase activity and lower lipoprotein lipase activity as compared to those in the control animals. Treatment of G-400 and standard drug to the animals reduced the TC and TG levels and normalized the respective enzymes significantly $(\mathrm{p}<0.05)$ to the control animals.

The activities of carbohydrate metabolic enzymes and level of glycogen in the liver of normal, diabetic and drug treated rats are given in Figure 5. The decreased activities of glucose-6-phosphate dehydrogenase and malic enzyme and the concentration of glycogen observed in the liver of diabetic rats as compared with normal control rats were reversed by treatment with G400 and glibenclamide. Similarly, increased glucose-6phosphatase activity was improved to the near normal level by the treatment of G-400 and glibenclamide.

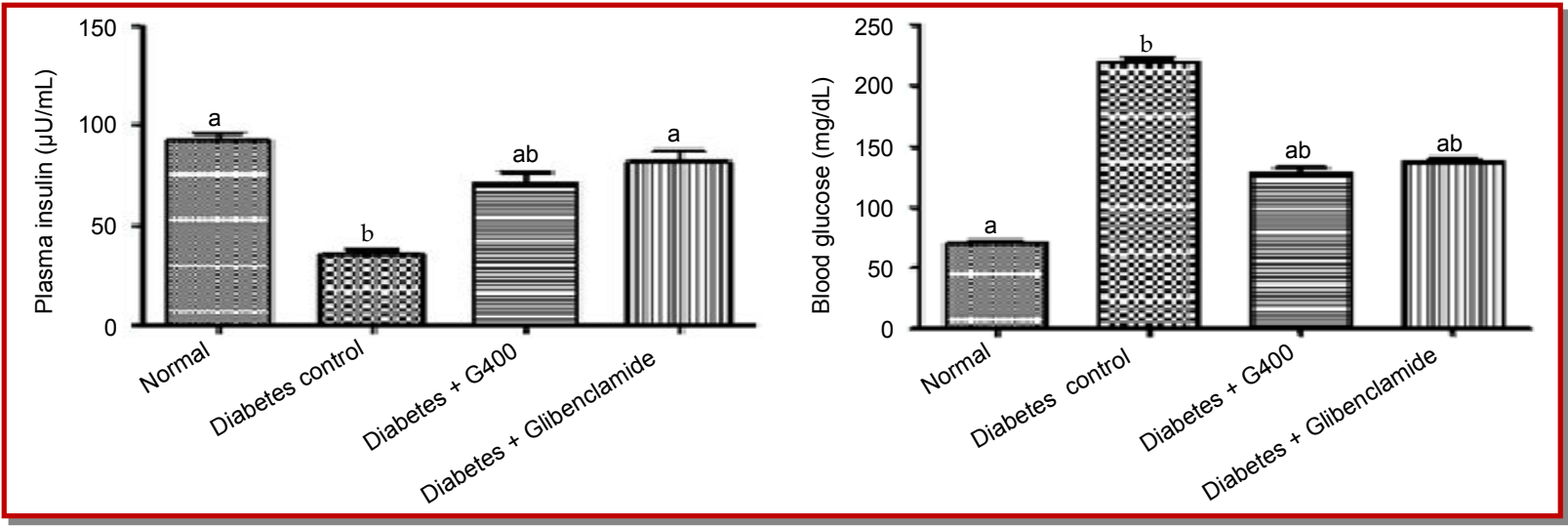

Figure 1: Effect of G-400 on the plasma glucose and insulin levels on streptozotocin treated rats

Streptozotocin-treated diabetic rats were treated with G-400 (100 mg/kg b.wt.) daily using an intragastric tube for 4 weeks. The results were compared with diabetic control rats (group 2) and normal control (group 1), where no STZ was administered. The positive control in the study comprises of rats administered with glibenclamide $(0.025 \mathrm{mg} / \mathrm{kg}$ b.wt.) daily using an intragastric tube for 4 weeks. Results are expressed as mean \pm SD of $\mathrm{n}=$ 4-6 independent assays. ${ }^{b} p<0.05$, statistically different from the control group, a $p<0.05$, statistically different from diabetic control 


\section{Discussion}

The present study demonstrated that oral administration of G-400 could improve not only the glucose level in streptozotocin-treated rats and thereby act as anti-diabetic agent, but also reduce the hyperlipidemia. We used streptozotocin to induce diabetes in rat. According to Szkudelski (2001), streptozotocin enters the B cell via a glucose transporter (GLUT2) and causes alkylation of DNA and induces increased supply of substrate for xanthine oxidase resulting into the formation of superoxide radicals, hydrogen peroxide, hydroxyl radicals and nitric oxide that inhibits aconitase activity and participates in DNA damage, ultimately leads to $\beta$ cell's destruction (Szkudelski, 2001). When animals being treated with G-400, significant improvement in the plasma insulin suggests secretagogue/ $\beta$ cells regeneration capacity of the drug or even the reduction of free radicals. Evidence from the early report suggests that G. sylvestrae, one of the constituents of G-400, is having insulin secretagogues action by increasing cell permeability rather than exocytosis
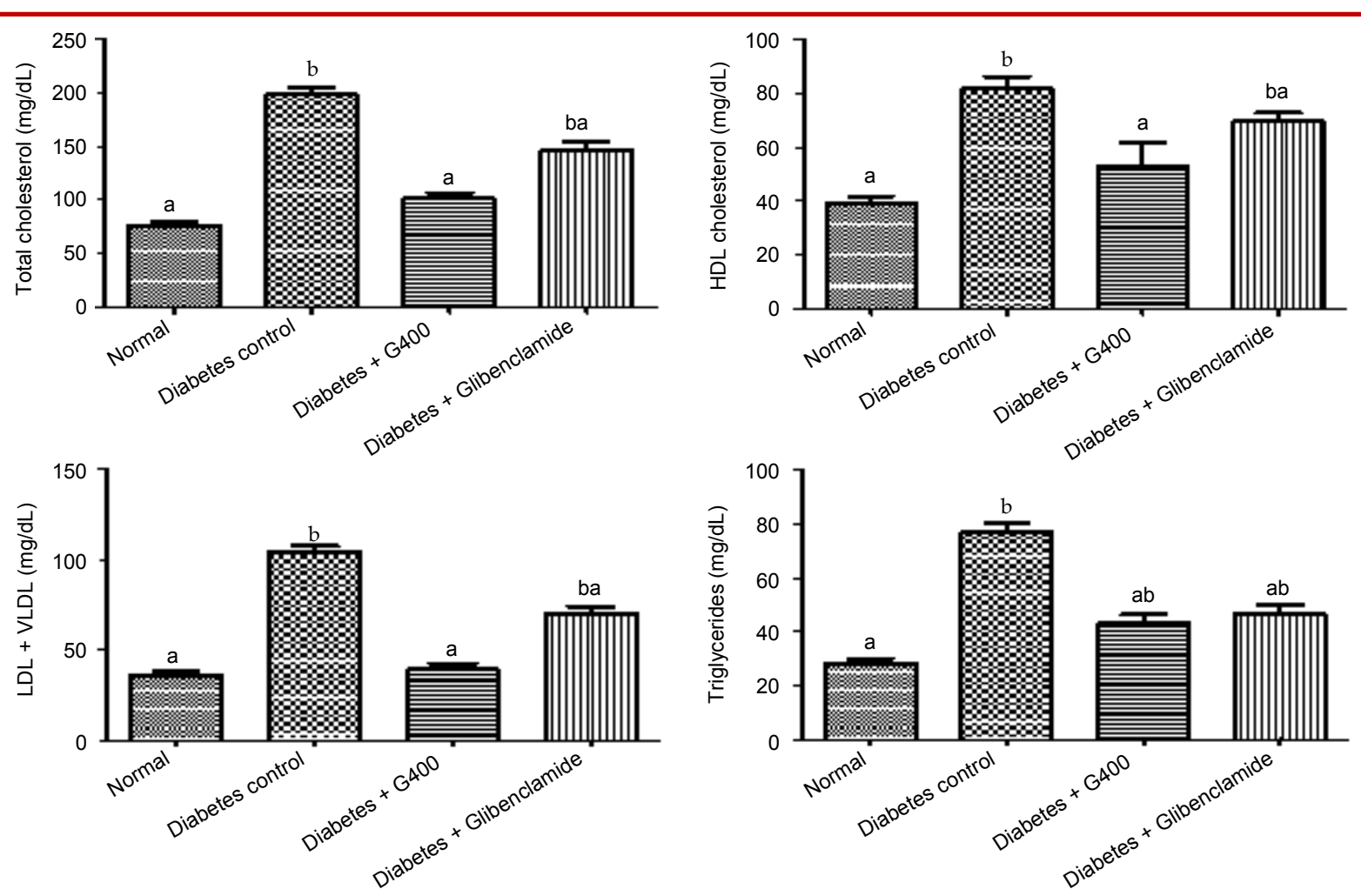

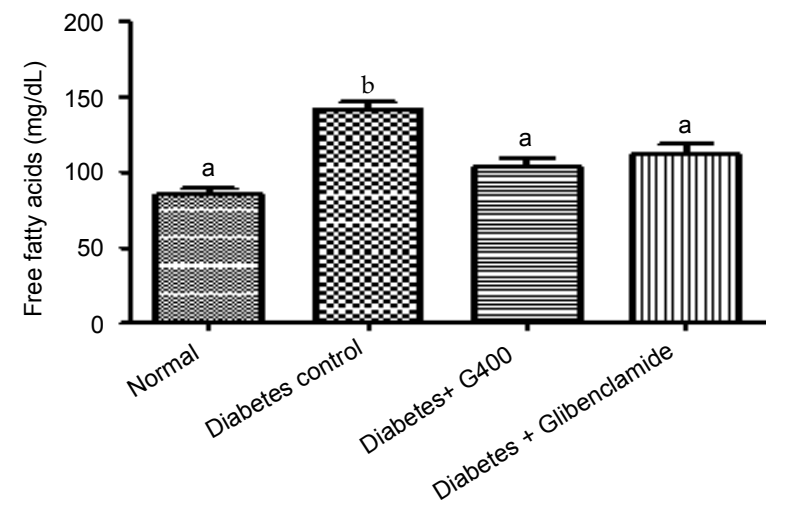

Figure 2: Effect of G-400 on the concentration of total cholesterol, HDL cholesterol, VLDL + LDL cholesterol, triglycerides and free fatty acids in blood samples

Streptozotocin-treated diabetic rats were treated with G-400 (100 mg/kg b.wt.) daily using an intragastric tube for 4 weeks. The results were compared with diabetic control rats (group 2) and normal control (group 1), where no streptozotocin was administered. The positive control in the study comprises of rats administered with glibenclamide $(0.025 \mathrm{mg} / \mathrm{kg}$ b.wt. $)$ daily using an intragastric tube for 4 weeks. Results are expressed as mean $\pm S D$ of $n=4-6$ independent assays. $b p<0.05$, statistically different from the control group, ap $<0.05$, statistically different from diabetic control 


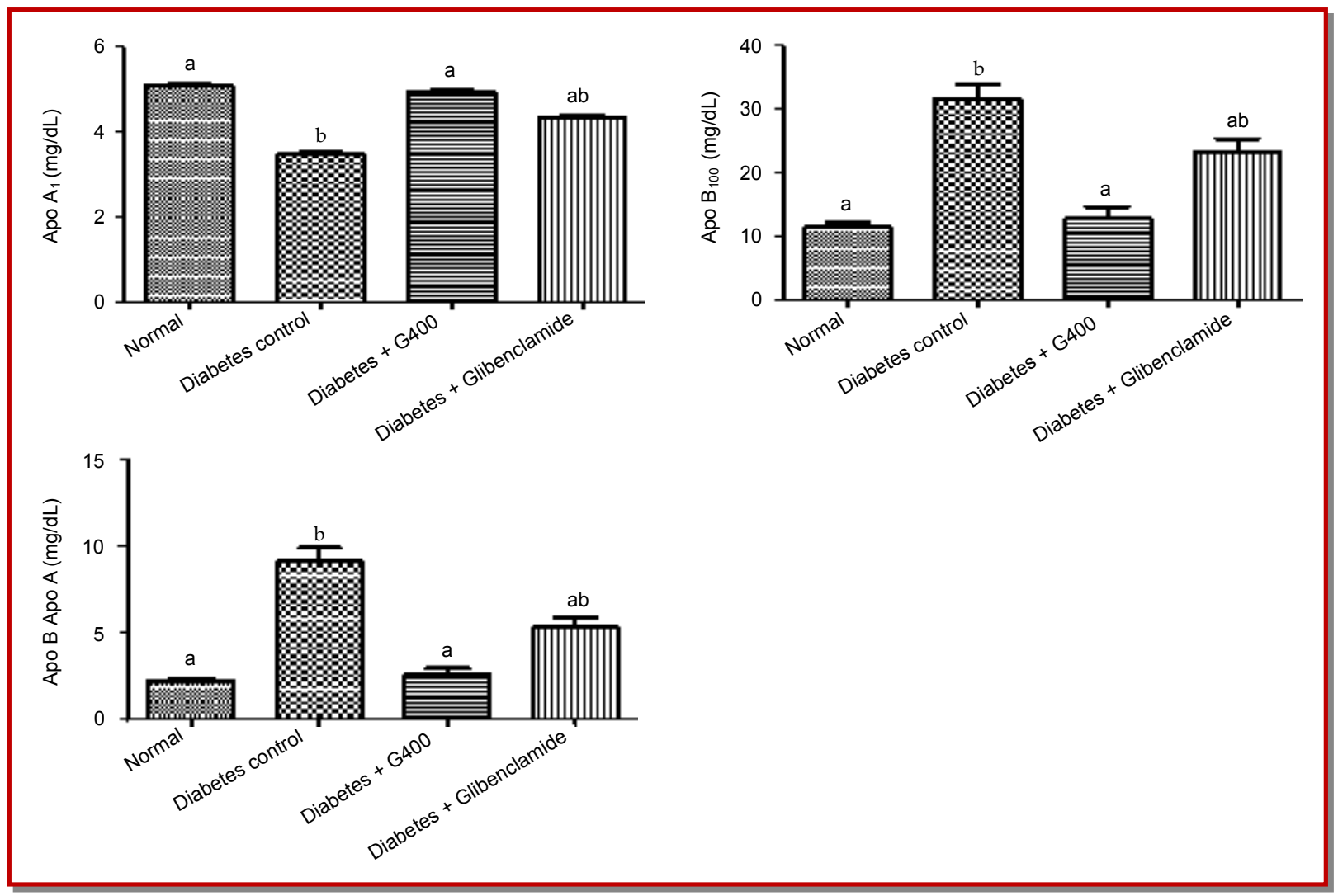

Figure 3: Effect of G-400 on apo A1, apo B100 and apo A1/apo B100 levels in blood samples

Streptozotocin-treated diabetic rats were treated with G-400 (100 mg/kg b.wt.) daily using an intragastric tube for 4 weeks. The results were compared with diabetic control rats (group 2) and normal control (group 1), where no streptozotocin was administered. The positive control in the study comprises of rats administered with glibenclamide $(0.025 \mathrm{mg} / \mathrm{kg}$ b.wt.) daily using an intragastric tube for 4 weeks. Results are expressed as mean \pm $\mathrm{SD}$ of $\mathrm{n}=4-6$ independent assays. $\mathrm{bp}<0.05$, statistically different from the control group, ap $<0.05$, statistically different from diabetic control

by regulated pathway (Persaud et al., 1999). In addition, E. officinalis can stimulate basal insulin output from the remaining beta cells within the pancreas (Nainet al., 2012). In an another study, the methanol extract of $G$. sylvestre leaf, and callus showed anti-diabetic activities through regenerating $\beta$ cells (Ahmed and Rao, 2010). Furthermore, constituents of G-400 were already reported to have high anti-oxidant potential.

Growing evidences showed a positive correlation of fasting insulin levels with obesity, systolic and diastolic blood pressure, triglyceride, $\beta$-lipoprotein cholesterol and pre- $\beta$-lipoprotein cholesterol levels (Burke et al., 1986). Hence, we measured the lipid profile in the serum (total, LDL, non-HDL, and HDL cholesterol and triglycerides) and free fatty acid along with the LDL to HDL ratio and our results suggest prominent hypolipidemic effect for G-400. This effect was the consequence of the synergic effect of G-400 constituents as evident from early study of S. oblonga (Bhat et al., 2012), G. sylvestre (Daisy et al., 2009), T. cordifolia (Stanely Mainzen Prince and Menon, 2003), E. officinalis (Augusti et al., 2001) and C. longa (Babu and Srinivasan, 1997).

The elevated apoprotein A, an integral protein of HDL and declined apoprotein B, an integral apoprotein of LDL in G-400 treated rat blood signify the antiatherogenic effect of the drug as previous study showed that apoB/apoA-I ratio represents the balance of proatherogenic and antiatherogenic lipoproteins (Lima et al., 2007). Current reports suggest that cholesterol balance, determined as the apoB/apoA-I ratio has repeatedly been shown as a better marker than lipids, lipoproteins and lipid ratios (Lima et al., 2007). As shown in Figure 3, G-400 treatment significantly reduced apo $\mathrm{B} /$ apo $\mathrm{A}$ ratio, indicates the efficacy of the drug as a hypolipidemic agent as well.

In order to check, whether the alterations in blood lipid levels correlated with tissue lipid content, we measured lipid profiles in hepatic tissues and the results found to be agreeing with blood lipid profile results. In addition, in order to reconfirm the resultant alteration in the metabolic changes following diabetes and therapy in blood and tissues, we analyzed corresponding enzyme activities in hepatic tissues of rats to affirm our results. Hypoglycemic effect of G-400 was affirmed by the low HMG-CoA reductase, the key regulatory enzyme in cholesterol biosynthesis, indicating reduced endogenous synthesis of cholesterol in liver, resulting in 


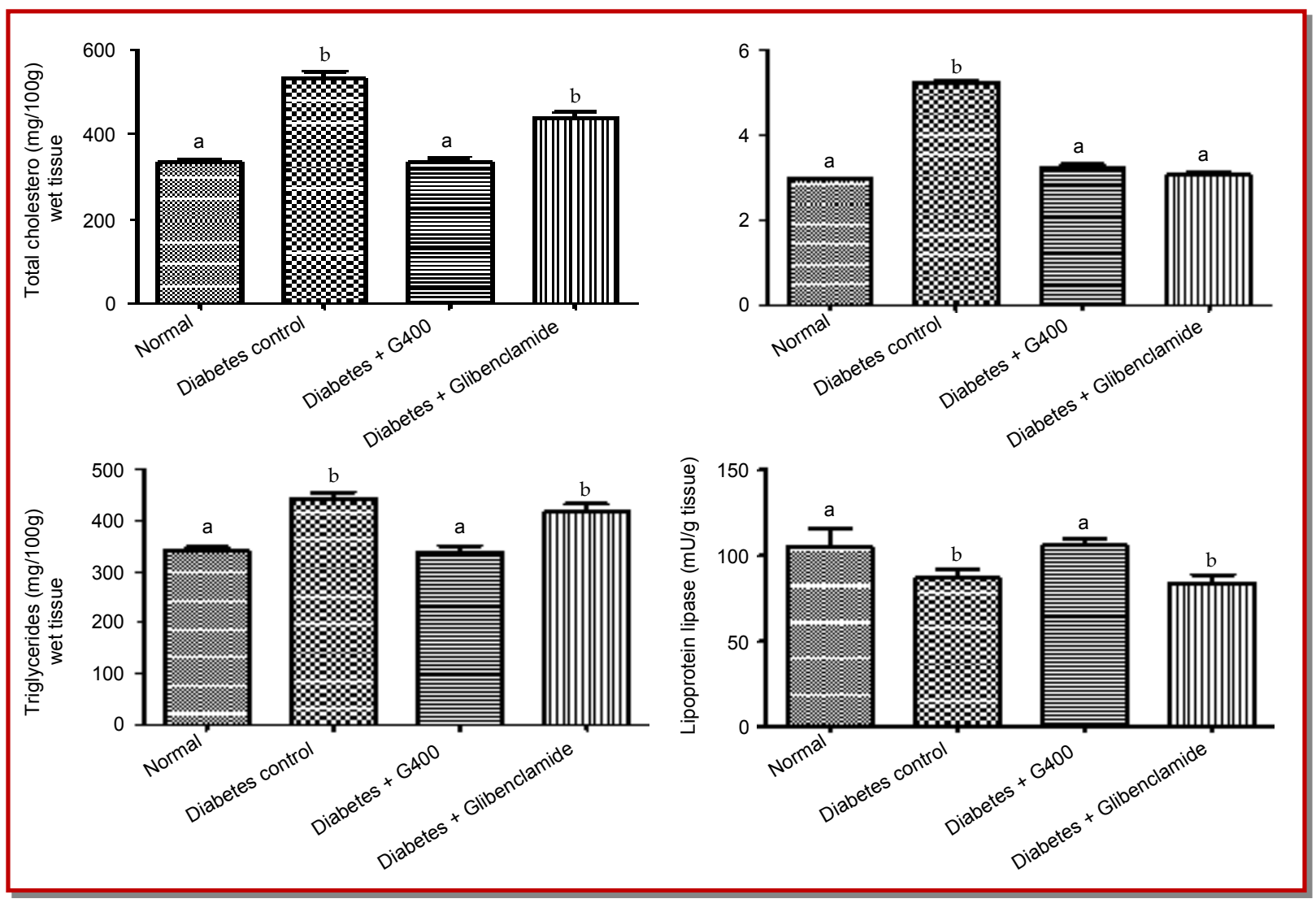

Figure 4: Effect of G-400 on the concentration of total cholesterol and triglycerides and the activities of HMG-Co A reductase in hepatic tissue

Streptozotocin-treated diabetic rats were treated with G-400 $(100 \mathrm{mg} / \mathrm{kg})$ daily using an intragastric tube for 4 weeks. The results were compared with diabetic control rats (Group 2) and normal control (Group 1), where no streptozotocin was administered. The positive control in the study comprises of rats administered with glibenclamide $(0.025 \mathrm{mg} / \mathrm{kg})$ daily using an intragastric tube for 4 weeks. Results are expressed as mean \pm SD of $\mathrm{n}=$ 4-6 independent assays. ${ }^{b} \mathrm{p}<0.05$, statistically different from the control group, ${ }^{\mathrm{a}} \mathrm{p}<0.05$, statistically different from diabetic control

decreased total hepatic cholesterol concentration. Importantly, glibenclamide treatment also reduced HMG-CoA reductase activity without significant decline in total concentration of cholesterol in liver, pointing out the effect is indirect and is associated with anti-diabetic action of the drug. The difference in G-400 action may be due to the higher cholesterol catabolism mediated by C. longa (Babu and Srinivasan, 1997) and E. officinalis (Augusti et al., 2001), the constituents of G400 .

It has been proposed that inhibition of HMG-CoA reductase leads to a reduction in the concentration of hepatic cholesterol and therefore, up regulation of LDL receptors resulted in internalization of not only LDL but also VLDL remnants (Sato and Takano, 1995), resulting a reduced plasma triglyceride concentration. We found a similar observation agreeing the consequential positive correlation between hepatic triglyceride and plasma triglyceride concentrations, reported by previous investigators (Nikkila et al., 1977).

The action of lipoprotein lipase on triglyceride-rich lipoproteins, generates free fatty acids that are either transported into the tissues or mixed with circulating free fatty acids. Accumulated evidences suggested that higher triglyceride concentration, and lower LPL activities are the determinants of small LDL size, the predictor of ischemic heart disease risk in diabetic patients. G-400 treatment not only reduced triglycerides and free fatty acids in blood and hepatic tissues, it also elevated LPL to near normal level as compared to diabetic control (Xu et al., 2008).

A decreased G6PD/malic enzyme activity leads to decreased NADPH and makes cells very sensitive to oxidant damage, one of the major reasons for pathophysiology of diabetes mellitus was improved with G-400 treatment for 4 weeks. Recovered malic enzyme activities, an important player for that regulate insulin secretion ( $\mathrm{Xu}$ et al., 2008) substantiate the improved insulin secretion in the drug treated group and this effect was reflected in plasma insulin level as well.

In addition, elevated glucose 6 phosphatase, one of the key enzymes that determine the endogenous glucose production is a consistent feature of type 2 diabetes is 


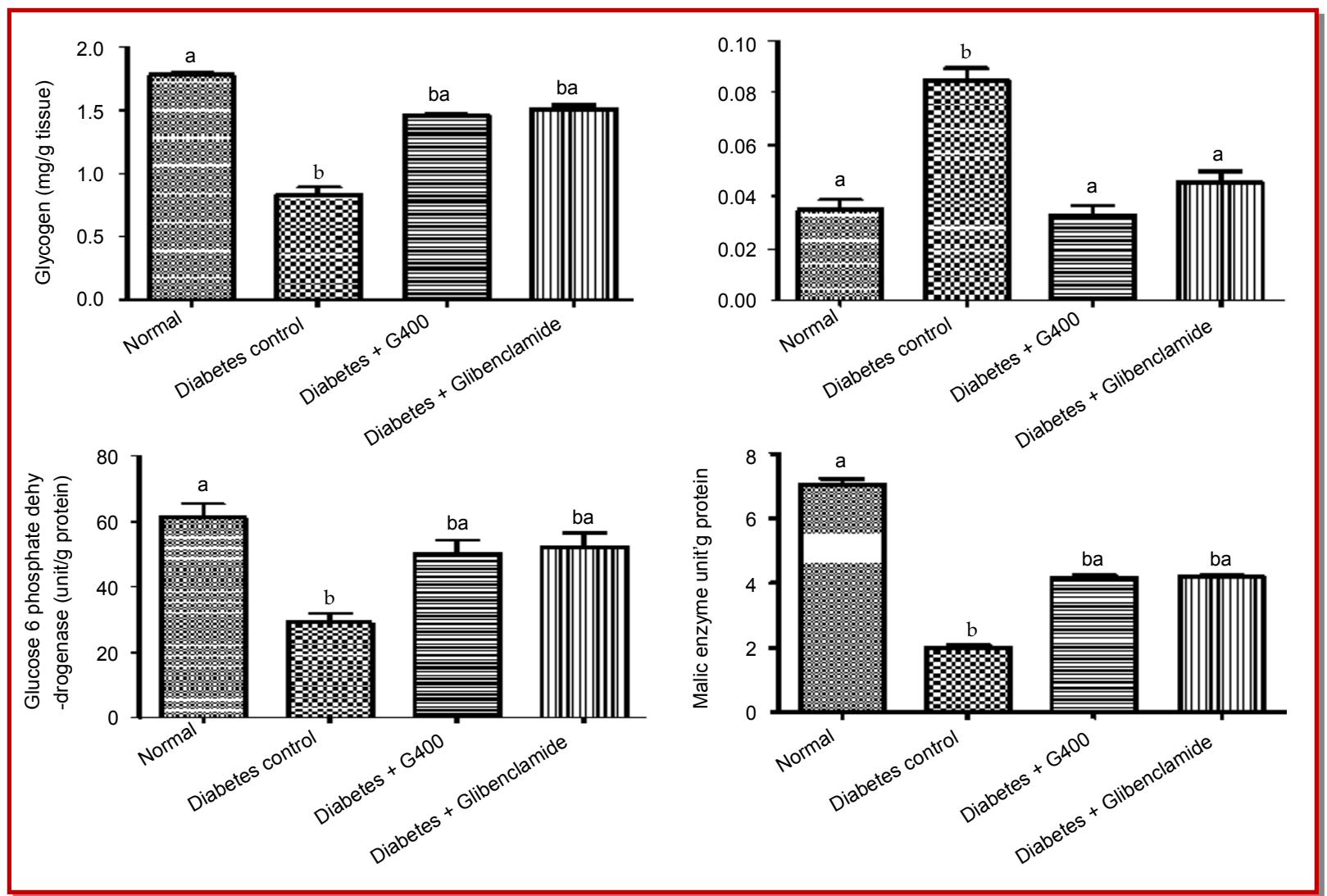

Figure 5: Effect of G-400 on glycogen level and the activities of glucose-6-phosphatase, glucose-6-phosphate dehydrogenase and malic enzyme in hepatic tissue

Streptozotocin-treated diabetic rats were treated with G-400 $(100 \mathrm{mg} / \mathrm{kg})$ daily using an intragastric tube for 4 weeks. The results were compared with diabetic control rats (Group 2) and normal control (Group 1), where no streptozotocin was administered. The positive control in the study comprises of rats administered with glibenclamide $(0.025 \mathrm{mg} / \mathrm{kg}$ b.wt.) daily using an intragastric tube for 4 weeks. Results are expressed as mean \pm SD of $n=4-6$ independent assays. ${ }^{b} p<0.05$, statistically different from the control group, ap $<0.05$, statistically different from diabetic control

the consequence of increased differences in insulin sensitivity, resulted from increased fatty acid oxidation and hyperglycaemia. Therefore, reduced glucose-6phosphatase activity in our study especially in those animals treated with G-400 and glibenclamide suggested better recovery of animal from diabetic insult. Growing evidence showed that insulin can stimulates glycogen synthesis in the liver and skeletal muscle and thereby increase hepatic glycogen level and the improved hepatic glycogen content of G-400 treated animal support the improve hepatic function and insulin action. Furthermore, our clinical trial with this drug in small populations showed significant recovery in diabetic patients (Kurian et al., 2014).

\section{Conclusion}

The poly-herbal drug, G-400 has potential hypoglycemic and anti-diabetic activity beside it reduced the hyperlipidemia. Hypolipidemic and anti-diabetic effect may be due to the effect of active constituents in the combination which may be responsible not only for the scavenging free radicals liberated by streptozotocin in diabetic rats but also by stimulating insulin secretion.

\section{Ethical Issue}

The experimental protocol has been approved by the institutional animal ethics committee and by the regulatory body of the government (Reg. No. 817/ac/ CPCSEA, dated 06/08/04).

\section{Conflict of Interest}

The authors have no financial conflicts of interest.

\section{References}

Ahmed AB, Rao ASRao MV. In vitro callus and in vivo leaf extract of Gymnema sylvestre stimulate beta-cells regeneration and anti-diabetic activity in Wistar rats. Phytomedicine 2010; 17: 1033-39. 
Allain CC, Poon LS, Chan CS, Richmond WFu PC. Enzymatic determination of total serum cholesterol. Clin Chem. 1974; 20: 470-75.

Augusti KT, Arathy SL, Asha R, Ramakrishanan J, Zaira J, Lekha V, Smitha S Vijayasree VM. A comparative study on the beneficial effects of garlic (Allium sativum Linn), amla (Emblica officinalis Gaertn) and onion (Allium cepa Linn) on the hyperlipidemia induced by butter fat and beef fat in rats. Indian J Exp Biol. 2001; 39: 760-66.

Babu PS, Srinivasan K. Hypolipidaemic action of curcumin, the active principle of turmeric (Curcuma longa) in streptozotocin induced diabetic rats. Mol Cell Biochem. 1997; 166: 169-75.

Babu PS, Stanely Mainzen Prince P. Antihyperglycaemic and anti-oxidant effect of hyponidd, an ayurvedic herbomineral formulation in streptozotocin-induced diabetic rats. J Pharm Pharmacol. 2004; 56: 1435-42.

Bhat BM, C VR, D'Souza V Manjrekar PA. Anti-diabetic and hypolipidaemic effect of Salacia oblonga in streptozotocin induced diabetic rats. J Clin Diagn Res. 2012; 6: 1685-87.

Burke GL, Webber LS, Srinivasan SR, Radhakrishnamurthy B, Freedman DS, Berenson GS. Fasting plasma glucose and insulin levels and their relationship to cardiovascular risk factors in children: Bogalusa heart study. Metabolism. 1986; 35: $441-46$.

Daisy P, Eliza J, Mohamed Farook KA. A novel dihydroxy gymnemic triacetate isolated from Gymnema sylvestre possessing normoglycemic and hypolipidaemic activity on STZ-induced diabetic rats. J Ethnopharmacol. 2009; 126: 33944 .

Edgerton DS, Johnson KM, Cherrington AD. Current strategies for the inhibition of hepatic glucose production in type 2 diabetes. Front Biosci (Landmark Ed) 2009; 14: 1169-81.

Falholt K, Lund B, Falholt W. An easy colorimetric micro method for routine determination of free fatty acids in plasma. Clin Chim Acta. 1973; 46: 105-11.

Folch J, Lees MS, Loane Stanley GH. A simple method for the isolation and purification of total lipids from animal tissues. J Biol Chem. 1957; 226: 497-509.

Garland RC, Cori CF, Chang HW. Relipidation of phospholipid-depleted microsomal particles with high glucose 6-phosphatase activity. Proc Natl Acad Sci. 1974; 71: 3805-09.

Kurian GA, Philip S, Varghese T. Effect of aqueous extract of the Desmodium gangeticum dc root in the severity of myocardial infarction. J Ethnopharmacol. 2005; 97: 457-61.

Kurian G A, Manjusha V, Sunitha SN, Varghese T, Padikkala J. Short-term effect of G-400, polyherbal formulation in the management of hyperglycemia and hyperlipidemia conditions in patients with type 2 diabetes mellitus. Nutrition. 2014; 30: 1158-64.

Lima LM, Carvalho M, Sabino Ade P, Mota AP, Fernandes AP, Sousa MO. Apo B/Apo A1 ratio in central and peripheral arterial diseases. Arq Bras Endocrinol Metabol. 2007; 51: 1160 -65 .

Lowry $\mathrm{OH}$, Rosebrough NJ, Farr AL, Randall RJ. Protein measurement with the folin phenol reagent. J Biol Chem. 1951; 193: 265-75.

Mayes PA, Fells JM. The functional status of lipoprotein lipase in rat liver. Biochem. J. 1968; 108: 483-87.

Modak M, Dixit P, Londhe J, Ghaskadbi S, Devasagayam TP. Indian herbs and herbal drugs used for the treatment of diabetes. J Clin Biochem Nutr. 2007; 40: 163-73.

Nain P, Saini V, Sharma S, Nain J. Antidiabetic and antioxidant potential of Emblica officinalis Gaertn. Leaves extract in streptozotocin-induced type 2 diabetes mellitus ( $\mathrm{t} 2 \mathrm{dm}$ ) rats. J Ethnopharmacol. 2002; 142: 65-71.

Nikkila EA, Huttunen JKEhnholm C. Postheparin plasma lipoprotein lipase and hepatic lipase in diabetes mellitus. Relationship to plasma triglyceride metabolism. Diabetes. 1977; 26: 11-21.

Pari L, Saravanan R. Antidiabetic effect of diasulin, a herbal drug, on blood glucose, plasma insulin and hepatic enzymes of glucose metabolism in hyperglycaemic rats. Diabetes Obes Metab. 2004; 6: 286-92.

Persaud SJ, Al-Majed H, Raman A, Jones PM. Gymnema sylvestre stimulates insulin release in vitro by increased membrane permeability. J Endocrinol. 1999; 163: 207-12.

Pongratz RL, Kibbey RG, Shulman GI, Cline GW. Cytosolic and mitochondrial malic enzyme isoforms differentially control insulin secretion. J. Biol. Chem. 2007; 282: 200-07.

Rakieten N, Rakieten ML, Nadkarni MV. Studies on the diabetogenic action of streptozotocin (nsc-37917). Cancer Chemother Rep. 1963; 29: 91-98.

Sato R, Takano T. Regulation of intracellular cholesterol metabolism. Cell Struct Funct. 1995; 20: 421-27.

Schroeder L., Christoff M, Levy H. Glucose-6-phosphate dehydrogenase from rabbit erythrocytes. Biochim Biophys Acta. 784; 48: 1984-85.

Stanely Mainzen Prince P, Menon VP. Hypoglycemic and hypolipidaemic action of alcohol extract of Tinospora cordifolia roots in chemical induced diabetes in rats. Phytother Res. 2003; 17: 410-13.

Szkudelski T. The mechanism of alloxan and streptozotocin action in b-cells of the rat pancreas. Physiol Res. 2001; 50: 537 -46 .

Trinder P. Determination of blood glucose using 4-amino phenazone as oxygen acceptor. J Clin Pathol. 1969; 22: 246.

Van Handel E. Suggested modifications of the micro determination of triglycerides. Clin Chem.1961; 7: 249-51.

Warnick GR, Albers JJ. A comprehensive evaluation of the heparin-manganese precipitation procedure for estimating high density lipoprotein cholesterol. J Lipid Res. 1978; 19: 6576.

Xu J, Han J, Long YS, Lock J, Weir GC, Epstein PN, Liu YQ. Malic enzyme is present in mouse islets and modulates insulin secretion. Diabetologia. 2008; 51: 2281-89.

Author Info
Auno A. Kurian (Principal contact)

Gino A. Kurian (Principal contact)

, e-mail: ginokurian@hotmail.com 


\section{Your feedback about this paper}

1. Number of times you have read this paper 0

2. Quality of paper Click

3. Your comments

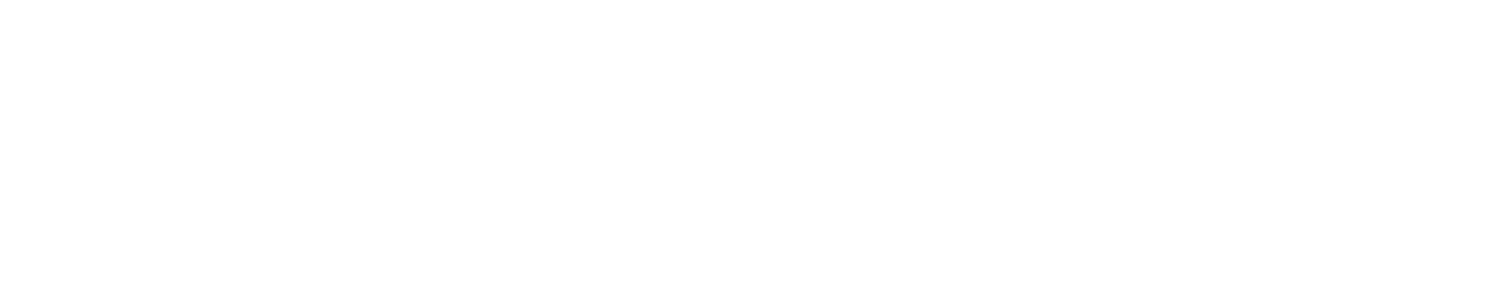

